\title{
ESTUDO DOS EFEITOS DE PARÂMETROS ESTRUTURAIS NOS PERFIS DE ESCOAMENTO EM REATORES FOTOCATALÍTICOS MICRO-ESTRUTURADOS
}

\author{
A. P. COURI ${ }^{1}$, B. RAMOS ${ }^{2}$ e A. C. S. C. TEIXEIRA ${ }^{3}$ \\ ${ }^{1}$ Aluno de Graduação da Escola Politécnica da USP, Departamento de Engenharia Química \\ ${ }^{2}$ Pós-Doutorando da Escola Politécnica da USP, Departamento de Engenharia Química \\ ${ }^{3}$ Professor-Doutor da Escola Politécnica da USP, Departamento de Engenharia Química \\ E-mail para contato: atieh.couri@usp.br
}

\begin{abstract}
RESUMO - Reatores fotocatalíticos foram analisados quanto a seus perfis de escoamento através de experimentos de distribuição de tempo de residência. A micro-estruturação dos espaços reacionais deu-se através do recheio desses reatores com esferas de diâmetros apropriados. Notou-se aumento da performance dos reatores com a diminuição do diâmetro hidráulico do escoamento, indício de que tais configurações podem introduzir os benefícios de dispositivos microfluídicos em sistemas macrométricos. Discutiu-se o potencial de aplicação no domínio dos Processos Oxidativos Avançados.
\end{abstract}

\section{INTRODUÇÃO}

O tratamento de poluentes orgânicos em efluentes provenientes de plantas químicas é um foco de atenção da indústria devido à sua potencial toxicidade ao meio ambiente. Visto que o tratamento de efluentes industriais normalmente visa apenas à conformação à legislação ambiental, é essencial maximizar a eficiência dos processos mantendo os custos operacionais tão baixos quanto possível (Ramos, 2014). Os processos fotoquímicos, em especial a fotocatálise, apresentam-se como opção viável sobretudo se consideradas as numerosas configurações que reatores fotocatalíticos podem assumir para otimizar o fluxo fotônico e, consequentemente, as taxas de conversão (McCullagh et al., 2011).

Neste contexto, estuda-se a distribuição do tempo de residência dentro de reatores fotocatalíticos solares para tratamento de águas contaminadas, em função dos parâmetros estruturais dos recheios utilizados para a micro-estruturação. Tais reatores apresentam potencial para intensificar as reações que neles ocorrem além de evitar o consumo energético associado à geração de radiação artificial, o que pode representa até $70 \%$ dos custos operacionais, segundo Malato et al. (2004). Apesar de preliminar, esta análise é fundamental para a compreensão completa destes sistemas no tocante à sua aplicabilidade para tratamento de efluentes contaminados.

\subsection{Reatores fotocatalíticos micro-estruturados}

A miniaturização de espaços reacionais tem sido extensivamente estudada nas últimas décadas como instrumento de intensificação de processos pertencentes a diversas áreas de 
pesquisa, como mostrado, por exemplo, nos trabalhos de Neumann e Zeitler (2012) e Pohar e Plazl (2009). A redução das dimensões características de um reator, além do consequente aumento de superfície específica de troca, resulta numa diminuição significativa das limitações de transporte de calor (Schubert et al., 2001), massa (Aubin e Xuereb, 2009) e quantidade de movimento (Rouge et al., 2001).

A micro-estruturação do espaço reacional de reatores de escala macrométrica permite obter um compromisso entre os benefícios dos micro-reatores, do ponto de vista da intensificação de processos, e suas principais limitações para amplo uso industrial, como a vazão reduzida a microlitros, o alto gasto energético para o bombeamento e o elevado custo de produção. $\mathrm{O}$ domínio da fotocatálise heterogênea é particularmente beneficiado pela microestruturação graças à absorção mais eficiente e homogênea de fótons no volume reacional, em relação a fotorreatores convencionais, e à extensa superfície de contato entre as espécies reativas e um catalisador imobilizado nas paredes da estrutura do reator, extinguindo limitações no transporte de massa externo (Ramos, 2014).

Um reator tubular comum pode ser micro-estruturado ao rechear-se o volume interno com estruturas compactas nas quais o escoamento pelos seus interstícios seja caracterizado por um diâmetro hidráulico de escala micrométrica. No exemplo da Figura 1, a seção transversal de um arranjo compacto de esferas no seio do reator (ou seja, desprezando-se os efeitos de parede) define interstícios de escoamento, preenchidos em azul. A área de cada interstício $\left(A_{g a p}\right)$ é definida pela Equação 1, em que $r_{p}$ é o raio da partícula esférica, enquanto o perímetro de um interstício $\left(P_{g a p}\right)$ é definido pela Equação 2. Substituindo as Equações 1 e 2 na Equação 3, que define diâmetro hidráulico $\left(d_{h}\right)$, encontra-se a expressão que relaciona o raio das partículas com o diâmetro hidráulico do escoamento em questão. Nota-se que, para recheios cujos raios variam entre 0,5 e 3,0 mm, os diâmetros hidráulicos situam-se entre aproximadamente 100 e $620 \mu \mathrm{m}$, caracterizando um micro-escoamento.

Figura 1 - Seção transversal de leito recheado com esferas em arranjo compacto.

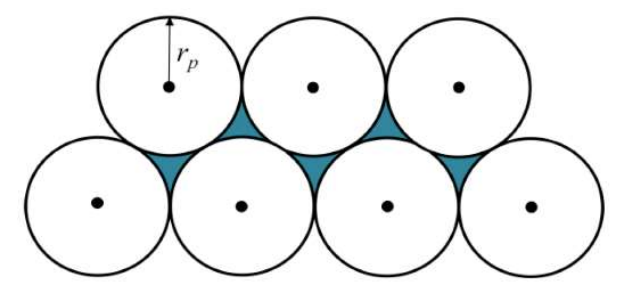

$$
\begin{aligned}
& A_{\text {gap }}=(\sqrt{3}-\pi / 2) r_{p}^{2} \\
& P_{\text {gap }}=\pi r_{p} \\
& d_{h}=4 \frac{A_{\text {gap }}}{P_{\text {gap }}}=\left(\frac{4 \sqrt{3}-2 \pi}{\pi}\right) r_{p} \cong 0,2053 r_{p}
\end{aligned}
$$

\subsection{Distribuição do tempo de residência (DTR)}

A distribuição do tempo de residência indica o histórico, à saída do reator, de cada porção de fluido que nele foi inserida. A metodologia proposta por Fogler (2005) para determinação 
desta distribuição baseia-se na injeção de um pulso de marcador (idealmente similar a uma função delta de Dirac) na entrada do reator e no registro da concentração do marcador na saída. A curva $C(t)$ obtida é então normalizada segundo a Equação 4, que gera a distribuição $E(t)$ denominada função densidade de probabilidade do tempo de residência:

$$
E(t)=\frac{C(t)}{\int_{0}^{\infty} C(t) d t}
$$

O tempo de residência médio $\left(t_{m}\right)$ é então definido pela Equação 5 e pode ser usado em seguida para definir a variância da dispersão $\left(\sigma^{2}\right)$, conforme mostrado pela Equação 6 .

$$
\begin{aligned}
t_{m} & =\frac{\int_{0}^{\infty} t E(t) d t}{\int_{0}^{\infty} E(t) d t}=\int_{0}^{\infty} t E(t) d t \\
\sigma^{2} & =\int_{0}^{\infty}\left(t-t_{m}\right)^{2} E(t) d t
\end{aligned}
$$

Os parâmetros $t_{m}$ e $\sigma^{2}$ permitem avaliar a idealidade do escoamento em reatores tubulares sem ou com recheio (PFRs e PBRs, respectivamente), assim como a presença de problemas de dispersão (zonas mortas, caminhos preferenciais de escoamento e difusão axial). É importante notar que o tempo de residência médio pode não corresponder ao tempo espacial $(\tau)$, definido pela Equação 7 como a razão entre o volume de escoamento $(V)$ e a vazão volumétrica $(Q)$.

$$
\tau=V / Q
$$

\section{MATERIAIS E MÉTODOS}

Os reatores fotoquímicos empregados neste trabalho são reatores tubulares em vidro borossilicato (Per-lab) transparente à radiação UV próximo. Dois tamanhos de reator foram testados: diâmetros internos de 17,6 e 29,2 mm (espessura de parede 1,2 e 1,4 mm, respectivamente), ambos com $300 \mathrm{~mm}$ de comprimento. Estes reatores foram recheados com quatro tamanhos de esferas transparentes de borossilicato em arranjos compactos, cujos diâmetros $(1,3,5$ e $6 \mathrm{~mm})$ atendem às condições de micro-escoamento a serem testadas. A Figura 2 (Ramos, 2014) ilustra a geometria e a disposição do reator durante os experimentos. A Figura 3 é um esquema do arranjo experimental utilizado para a determinação da DTR. Para o bombeamento de água destilada, foi utilizada uma bomba peristáltica de marca Provitec e modelo DM 5900 AX-D regulada a uma vazão constante de $33,1 \mathrm{~mL} \mathrm{~min}^{-1}$. As tubulações e conexões utilizadas foram majoritariamente mangueiras de $0,8 \mathrm{~mm}$ de diâmetro interno em teflon, que apresentam menor risco de adsorção do corante-marcador em suas paredes em relação a mangueiras tradicionais de silicone. Ainda assim, tubos de silicone de 0,5 mm foram utilizados em trechos curtos onde um acesso mais fácil era requerido para a injeção do marcador ou a amostragem da corrente de saída do reator (ambas realizadas com uma seringa simples).

A cada experimento, injetou-se um pulso de $1,0 \mathrm{~mL}$ de solução aquosa $8,51 \times 10^{-1} \mathrm{mmol}$ $\mathrm{L}^{-1}$ de alaranjado de metila (Sigma-Aldrich) à corrente de água destilada na entrada do reator. A coleta de amostras de aproximadamente $1,0 \mathrm{~mL}$, coletadas por gotejamento ao longo de dez segundos, foi feita na saída do reator a intervalos de tempo pré-determinados. 


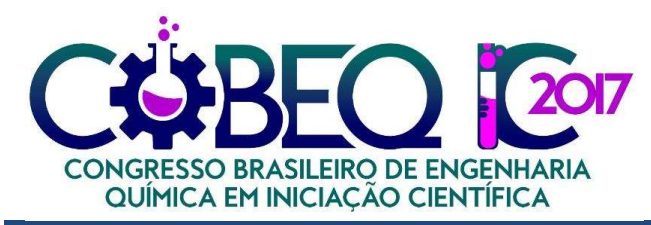

XII Congresso Brasileiro de Engenharia Química
em Iniciação Científica
UFSCar - São Carlos - SP
16 a 19 de Julho de 2017

Figura 2 - Disposição do fotorreator tubular e do recheio utilizados.

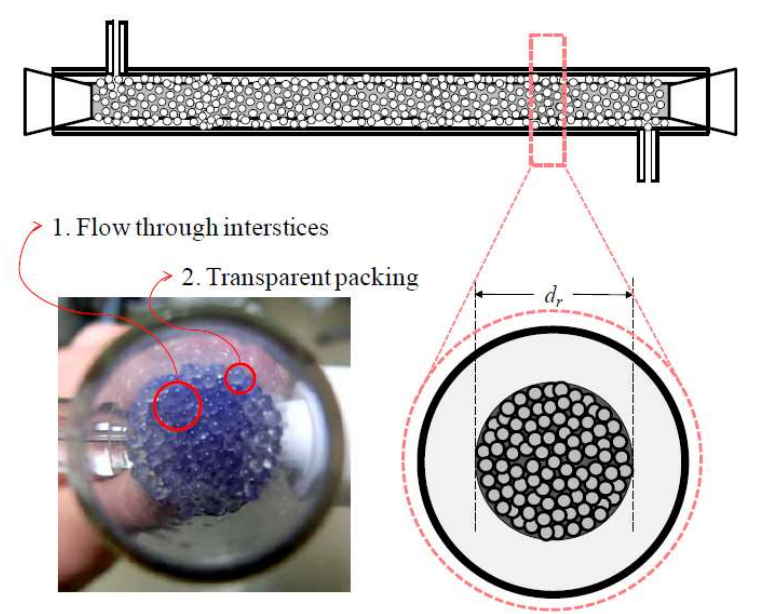

Figura 3 - Esquema do arranjo experimental para determinação da DTR.

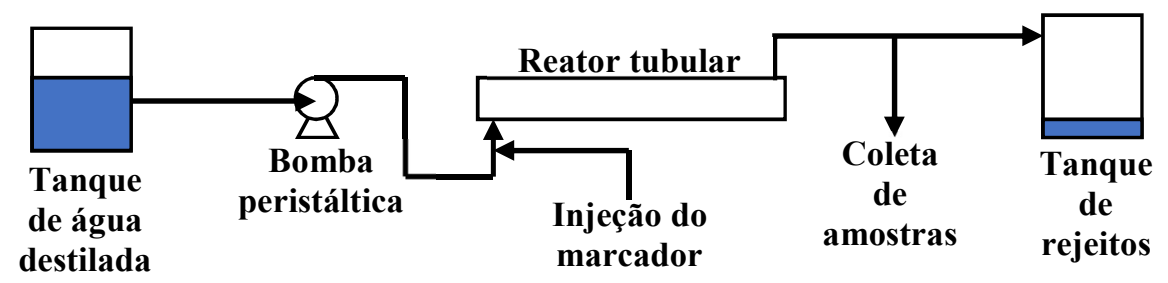

Todas as amostras foram diluídas em água destilada e analisadas quanto à concentração de alaranjado de metila em um espectrofotômetro UV-visível Varian modelo Cary 50 Probe através de uma curva de calibração previamente preparada.

\section{RESULTADOS E DISCUSSÃO}

As curvas de distribuição do tempo de residência (função $E(t)$ ) para os dois reatores analisados estão representadas na Figura 4. Para simplificar a análise, os reatores de diâmetro interno de 29,2 e 17,6 mm serão chamados concisamente de reatores "grande" e "pequeno". Nota-se que nenhum dos arranjos apresentou curto-circuito, recirculação interna nem formação de caminhos preferenciais de escoamento, o que teria gerado picos secundários. Para ambos os reatores, o experimento sem qualquer recheio (i.e. com os reatores não empacotados) resultou em curvas com "caudas" que se prolongam para além da duração do experimento, indicando a estagnação de uma porção do fluido (e, consequentemente, do marcador utilizado) em regiões com pouca circulação. As curvas referentes aos arranjos empacotados apresentam picos próximos, relativamente simétricos e com largura decrescente conforme se diminui o diâmetro das esferas, sugerindo que a presença do recheio produz escoamentos tipo pistão. Isto pode ser explicado pela segmentação do fluxo em canais de escoamento menores, o que é intensificado pela redução do tamanho dos obstáculos. Quanto às curvas dos reatores sem recheio, a defasagem dos picos se justifica pelo maior volume disponível para escoamento, implicando tempos de residência maiores a vazões constantes. A largura superior dos picos, que passam a ser fortemente assimétricos, pode ser explicada por escoamentos próximos do regime laminar. 
Figura 4 - Resultados das determinações de DTR para ambos reatores em função de sua estruturação interna.

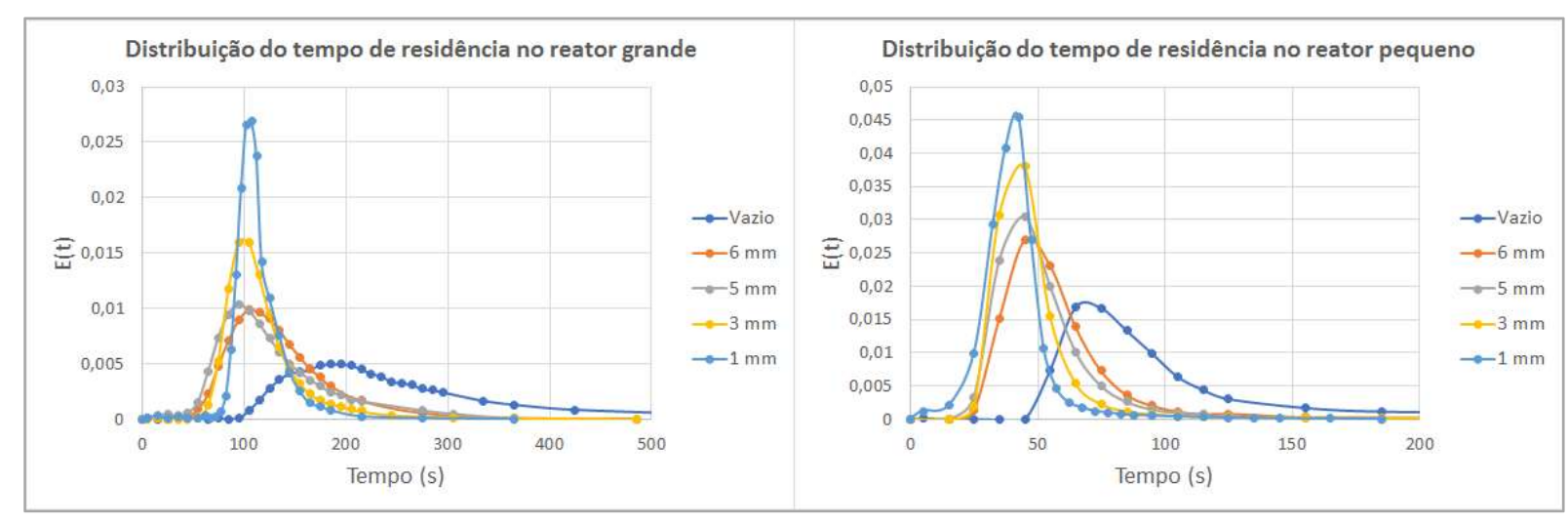

Tabela 1 - Resultados dos experimentos de DTR realizados

\begin{tabular}{|c|c|c|c|c|c|c|c|c|c|}
\hline Reator & $r_{p}(\mathrm{~mm})$ & $d_{h}(\mathrm{~mm})$ & $\mathrm{V}(\mathrm{mL})$ & $\tau(\mathrm{s})$ & $t_{m}(\mathrm{~s})$ & $\left|\tau-t_{m}\right|(\mathrm{s})$ & $\sigma^{2}\left(\mathrm{~min}^{2}\right)$ & $N_{d}(-)$ & $N_{T}(-)$ \\
\hline \hline \multirow{4}{*}{ Grande } & Ausente & 29,200 & 164,2 & 298 & 254 & 43 & 3,10 & N/A & N/A \\
\cline { 2 - 10 } & 3,0 & 0,616 & 67,2 & 122 & 132 & 10 & 0,99 & 0,08 & 8 \\
\cline { 2 - 10 } & 2,5 & 0,513 & 67,2 & 122 & 138 & 16 & 0,75 & 0,11 & 6 \\
\cline { 2 - 10 } & 1,5 & 0,308 & 64,2 & 116 & 122 & 6 & 0,68 & 0,04 & 13 \\
\cline { 2 - 10 } & 0,5 & 0,103 & 60,2 & 109 & 116 & 7 & 0,21 & 0,01 & 39 \\
\hline \hline \multirow{5}{*}{ Pequeno } & Ausente & 17,600 & 62,2 & 113 & 107 & 6 & 0,88 & N/A & N/A \\
\cline { 2 - 10 } & 3,0 & 0,616 & 31,2 & 57 & 60 & 4 & 0,30 & 0,07 & 9 \\
\cline { 2 - 10 } & 2,5 & 0,513 & 28,7 & 52 & 52 & 0 & 0,11 & 0,05 & 11 \\
\cline { 2 - 10 } & 1,5 & 0,308 & 24,7 & 45 & 52 & 7 & 0,33 & 0,05 & 11 \\
\cline { 2 - 10 } & 0,5 & 0,103 & 24,2 & 44 & 41 & 3 & 0,07 & 0,02 & 21 \\
\hline
\end{tabular}

A Tabela 1 traz os valores do tempo espacial $(\tau)$, do tempo médio de residência $\left(t_{m}\right)$ e da variância do tempo de residência $\left(\sigma^{2}\right)$ calculados a partir das curvas apresentadas na Figura 4 e das medidas dos volumes livres para escoamento (V). A diferença neste último se deve à presença de recheio e, entre os reatores recheados, a efeitos de parede que são mais significativos para diâmetros maiores de partícula. Observa-se similaridade entre os tempos de residência médios e os tempos espaciais para todos os arranjos exceto para o reator grande não recheado, cujo tempo de residência curto confirma a presença significativa de zonas de estagnação. Para reiterar a análise visual dos gráficos da Figura 4, dois modelos de escoamento (sintetizados por Levenspiel, 1999) foram ajustados aos dados experimentais: o modelo de dispersão e o modelo de tanques em série, de onde se tira respectivamente os números de dispersão $\left(N_{d}\right)$ e de tanques em série $\left(N_{T}\right)$ que são indicadores da idealidade de um escoamento pistão. Verifica-se que a redução do diâmetro hidráulico diminuiu a dispersão axial do corantemarcador nos reatores estudados e aumentou o número equivalente de tanques, comprovando a tendência, sugerida pela Figura 4, a perfis de escoamento pistonados cada vez mais próximos de um escoamento ideal. Estes modelos não puderam ser aplicados aos reatores sem recheio pois o escoamento, nestes casos, possui um caráter próximo do laminar, sendo um modelo de convecção pura mais adequado. 


\section{CONCLUSÃO}

Verificou-se que, ao menos sob a perspectiva dos perfis de escoamento, os reatores fotocatalíticos beneficiam-se significativamente da micro-estruturação. Além de contornar problemas tais como presença de zonas de volume morto e formação de caminhos preferenciais, a redução do diâmetro hidráulico provou-se valiosa no estreitamento da dispersão da DTR em tais reatores. Isto é especialmente relevante no tratamento de efluentes devido à necessidade de que todas as porções de fluido apresentem o mesmo histórico dentro dos sistemas de tratamento, garantindo a degradação homogênea e eficiente dos contaminantes ao evitar a formação de subprodutos indesejados resultantes de reações paralelas em regiões de retro-mistura.

Contempla-se, na sequência deste trabalho, a análise dos reatores fotocatalíticos microestruturados no tocante ao fluxo fotônico que alimentará as reações em seu interior. Pretendese avaliar este parâmetro através de medidas físicas (espalhamento de luz incidente) e químicas (actinometria) em relação à influência de diferentes materiais e tamanhos de recheio.

\section{REFERÊNCIAS}

AUBIN, J.; XUEREB, C. Micromixers. In: DIETRICH, T. R. Microchemical Engineering in Practice. John Wiley \& Sons: Hoboken, 2009.

FOGLER, H. S. Elements of Chemical Reaction Engineering. Quarta edição, Prentice Hall, 2005.

LEVENSPIEL, O. Chemical Reaction Engineering. Terceira edição, Wiley, 1999.

MALATO, S.; BLANCO, J.; MALDONADO, M. I.; FERNÁNDEZ, P.; ALARCON, D.; COLLARES, M.; FARINHA, J.; CORREIA, J. Engineering of solar photocatalytic collectors. Sol. Energ. Mat. Sol. Cells, vol. 77, p. 513-524, 2004.

MCCULLAGH, C.; SKILLEN, N.; ADAMS, M.; ROBERSON, P. K. J. Photocatalytic reactors for environmental remediation: a review. J. Chem. Technol. Biotechnol., vol. 86, p. 10021017, 2011.

NEUMANN, M.; ZEITLER, K. Application of Microflow Conditions to Visible Light Photoredox Catalysis. Org. Lett., vol. 14(11), p. 2658-2661, 2012.

POHAR, A.; PLAZL, I. Process Intensification through Microreactor Application. Chem. Biochem. Eng. Q., vol. 23(4), p. 537-544, 2009.

RAMOS, B. Intensification of photo-induced oxidation processes by using micro-structured reaction spaces. 2014. 150 f. Tese (Doutorado em Engenharia) - School of Materials and Chemical Technology, Tokyo Institute of Technology: Tóquio, 2014.

ROUGE, A.; SPOETZL, B.; GEBAUER, K.; SCHENK, R.; RENKEN, A. Microchannel reactors for fast periodic operation: the catalytic dehydration of isopropanol. Chem. Eng. Sci., vol. 56, p. 1419-1427, 2001.

SCHUBERT, K.; BRANDNER, J.; FICHTNER, M.; LINDER, G.; SCHYGULLA, U.; WENKA, A. Microstructured devices for applications in thermal and chemical engineering. Nanosc. Microsc. Therm., vol. 5, p. 17-39, 2001. 